\title{
Utstyr, laboratorieanalyser og medikamenter ved kommunale legevakter
}

\author{
Sammendrag \\ Bakgrunn. Det finnes ingen kunnskap \\ om hvilket utstyr leger på vakt ved \\ kommunale legevakter har tilgjengelig \\ for diagnostikk og behandling. Slik \\ kunnskap er nødvendig om det skal \\ fastsettes normer eller krav på områ- \\ det.
}

Materiale og metode. Et spørreskjema ble våren 2007 sendt til alle landets kommunale legevakter for å kartlegge hvilket utstyr, hvilke laboratorieanalyser og hvilke medikamenter som finnes ved legevaktene samt rutiner knyttet til hjerte-lunge-redning, laboratoriearbeid og medikamenthåndtering.

\section{Resultater. 223 av 261 legevakter} (85\%) besvarte skjemaet. 150 legevakter var samlokalisert med legekontorer i vertskommunen, 59 legevakter var frittstående og 14 var samlokalisert med akuttmottak. Legevakter som var samlokalisert med legekontorer hadde et bredere utvalg av utstyr, laboratorieanalyser og medikamenter enn frittstående legevakter. Vaktleger gjorde mye av laboratoriearbeidet ved samlokaliserte legevakter, kvalitetskontrollen ble utført av legekontorets personell. $27 \%$ av de frittstående legevaktene har ikke NOKLUS-medlemskap. Legene øvde avansert hjerte-lungeredning oftere enn årlig ved $52 \%$ av legevaktene, tilsvarende tall for frittstående legevakter var $40 \%$. Ved $74 \%$ av de frittstående legevaktene fikk hjelpepersonellet øvd minst årlig.

Fortolkning. Utstyrsnivå og analyserepertoar styres i stor grad av om legevaktlokalene er samlokalisert med et legekontor, men trolig også av avstand til ambulanse, sykehus og apotek. Manglende rutiner for laboratoriearbeid og sjeldne øvelser $\mathrm{i}$ avansert hjerte-lunge-redning kan medføre dårligere analysekvalitet og lavere kompetanse enn ønskelig.

\section{Ingrid Keilegavlen Rebnord}

ingrid.rebnord@isf.uib.no

Nasjonalt kompetansesenter for legevaktmedisin Kalfarveien 31

5018 Bergen

\section{Geir Thue}

Norsk kvalitetsforbedring av

laboratorievirksomhet utenfor sykehus (NOKLUS) og

Seksjon for allmennmedisin

Institutt for samfunnsmedisinske fag

Universitetet i Bergen

\section{Steinar Hunskår}

Nasjonalt kompetansesenter for legevaktmedisin og

Seksjon for allmennmedisin

Institutt for samfunnsmedisinske fag

Universitetet i Bergen

I Norge er legevakt et kommunalt ansvar, og den enkelte kommune skal organisere tjenesten og sørge for lokaler, utstyr og nødvendig hjelpepersonell for vakthavende lege. Forutsetninger for god medisinsk kvalitet $\mathrm{i}$ form av tilgjengelig utstyr og kontroll av utstyret er i liten grad undersøkt. Det finnes heller ingen forskrift, avtale eller nasjonal standard for hvilket utstyr og hva slags personell som skal være tilgjengelig for lege på vakt. Vi har derfor kartlagt hvilket utstyr, hvilke laboratorieanalyser og hvilke medikamenter som er tilgjengelig for diagnostikk og behandling samt rutinene knyttet til hjerte-lunge-redning, laboratoriearbeid og medikamenthåndtering.

\section{Materiale og metode}

Nasjonalt kompetansesenter for legevaktmedisin har opprettet et register over alle norske legevakter $(1,2)$. Våren 2007 ble det sendt et spørreskjema til 282 vertskommuner som ifølge registeret hadde egen eller interkommunal legevakttjeneste hele eller deler av døgnet. Det ble purret én gang.

Skjemaet var i fire deler, med forhåndsoppgitte svaralternativer og noe plass til tilføyelser. Alternativene ble valgt ut fra kunnskap om utstyrsnivå og rutiner ved legekontorer og enkelte større legevakter, og vi ba daglig leder stå for utfyllingen. I første del skulle det krysses av for hvilke typer utstyr som er tilgjengelig for vaktlegen kveld og natt. Vi spurte om hvor ofte henholdsvis leger og hjelpepersonell øvde på hjerte-lunge-redning. I andre del ba vi om informasjon om hvilke laboratorieanalyser som fantes ved legevakten, hvem som tar blodprøver og analyserer dem og hvordan prøvemateriale transporteres til eksternt laboratorium. Tredje del omhandlet hvilke rutiner legevakten har for opplæring av personalet i bruk av laboratorieutstyr, rutiner for kvalitetskontroll av laboratorieutstyret og om legevakten har eget medlemskap i Norsk kvalitetsforbedring av laboratorievirksomhet utenfor sykehus (NOKLUS). Videre ble det spurt om rutiner ved stikkskader og blodsøl og om de ansatte har tilbud om hepatitt B-vaksinasjon. I siste del spurte vi om rutiner for oppbevaring og utlevering av medikamenter. Til slutt skulle det krysses av for hvilke medikamenter som var tilgjengelig ved legevakten - av et utvalg på 30 medikamenter til intravenøs bruk, 27 til peroral bruk, tre til inhalasjon og tre lokalmidler.

På bakgrunn av opplysninger i legevaktregisteret (1) ble legevaktene gruppert etter om det var flere eller færre enn 10000 innbyggere i vaktdistriktet. I legevaktdistrikter med innbyggertall $>10000$ er det gjerne ansatt hjelpepersonell hele eller deler av døgnet, i økende grad med økende størrelse. I tillegg har vi tatt med i analysen om legevaktene var samlokalisert med legekontor eller akuttmottak eller var helt frittstående med eget lokale og hjelpepersonell. Innsamlede data ble analysert i statistikkprogrammet SPSS versjon 13.0 med enkle frekvensanalyser og krysstabeller.

\section{Resultater}

Etter gjennomgang av de 282 kommunene fra registerstudien viste det seg at 261 hadde egen legevakt på kveld og natt. Svarprosenten hos disse var $85(\mathrm{n}=223)$ og tilbudet på kveld og natt var omtrent identisk. 14 av legevaktene var samlokalisert med akutt-

\section{Hovedbudskap}

- Norske legevakter disponerer i stor grad utstyret sammen med fastlegekontorer

- Samlokaliserte legevakter er bredere utstyrt enn frittstående legevakter

- Ved samlokaliserte legevakter utføres kvalitetskontroll av laboratorieutstyr hyppigst av legekontorets personell, mens vaktlegen ofte utfører analysene

- Leger øver sjeldnere på avansert hjerte-lunge-redning ved store frittstående legevakter enn ved mindre samlokaliserte legevakter 
mottak og har i praksis tilgang på andre tjenester og utstyr enn de øvrige. De er derfor utelatt fra videre omtale. Gruppen av legevakter samlokalisert med legekontor ble delt $i$ to undergrupper ut fra innbygger- tall, mens det i gruppen av frittstående legevakter bare er legevakter som dekker minst 10000 innbyggere. Resultatpresentasjonen er basert på data fra disse tre gruppene $(\mathrm{n}=209)$.

Tabell 1 Antall legevakter med tilgjengelig utstyr fordelt etter størrelse på legevaktdistriktet og samlokalisering med legekontor

\begin{tabular}{|c|c|c|c|c|c|}
\hline & \multicolumn{2}{|c|}{$\begin{array}{l}\text { Totalmateriale } \\
\qquad(N=209)\end{array}$} & \multirow[t]{2}{*}{$\begin{array}{c}\text { Samlokaliserte } \\
<10000 \\
\text { innbyggere } \\
\text { (n = 125) }\end{array}$} & \multirow[t]{2}{*}{$\begin{array}{c}\text { Samlokaliserte } \\
>10000 \\
\text { innbyggere } \\
\text { (n=25) }\end{array}$} & \multirow[t]{2}{*}{$\begin{array}{l}\text { Frittstående } \\
\qquad(n=59)\end{array}$} \\
\hline & Antall & $(\%)$ & & & \\
\hline EKG & 207 & (99) & 125 & 25 & 57 \\
\hline Urinkateter & 207 & (99) & 123 & 25 & 59 \\
\hline Oftalmoskop/otoskop & 207 & (99) & 124 & 25 & 58 \\
\hline Intravenøs kanyle & 205 & (98) & 123 & 25 & 57 \\
\hline Utstyr sårsutur & 205 & (98) & 124 & 25 & 56 \\
\hline Gynekologisk utstyr & 203 & (97) & 122 & 25 & 56 \\
\hline Øyedråper & 201 & (96) & 119 & 25 & 57 \\
\hline Forstøverapparat & 201 & (96) & 122 & 24 & 55 \\
\hline Utstyr oksygentilførsel & 199 & (95) & 120 & 24 & 55 \\
\hline Permanent urinkateter & 199 & (95) & 119 & 24 & 56 \\
\hline Utstyr øyeskylling & 196 & (94) & 117 & 24 & 55 \\
\hline Bag/maske til ventilering & 196 & (94) & 117 & 23 & 56 \\
\hline Akuttsekk m/utstyr & 185 & (89) & 113 & 22 & 50 \\
\hline Defibrillator & 183 & (88) & 113 & 23 & 48 \\
\hline Bakteriologisk medium & 179 & (86) & 115 & 22 & 42 \\
\hline Rektalt termometer & 179 & (86) & 105 & 20 & 54 \\
\hline Synstavle & 177 & (85) & 112 & 22 & 43 \\
\hline PEF-måler & 174 & (83) & 111 & 19 & 44 \\
\hline Sug & 167 & (80) & 103 & 19 & 45 \\
\hline Tonometer & 166 & (79) & 109 & 23 & 34 \\
\hline Laryngelatuber & 164 & (78) & 97 & 20 & 47 \\
\hline Sterilisator & 160 & (76) & 91 & 22 & 47 \\
\hline Markeringsjakke/-vest & 154 & (74) & 97 & 22 & 35 \\
\hline Mikroskop & 153 & (73) & 100 & 17 & 36 \\
\hline Tamponadeutstyr & 148 & (71) & 93 & 20 & 35 \\
\hline Tolkingsmodul i EKG & 146 & (70) & 89 & 17 & 40 \\
\hline Lupelampe & 144 & (69) & 86 & 19 & 39 \\
\hline Rektoskop/anoskop & 145 & (69) & 105 & 20 & 20 \\
\hline Endotrakealtuber & 142 & (68) & 91 & 19 & 32 \\
\hline Virologisk medium & 133 & (64) & 95 & 16 & 22 \\
\hline Oksymeter & 134 & (64) & 83 & 9 & 42 \\
\hline$\emptyset$ retermometer & 128 & (61) & 67 & 14 & 47 \\
\hline Spirometer & 119 & (57) & 94 & 16 & 9 \\
\hline Utstyr laryngoskopi & 102 & (48) & 75 & 10 & 17 \\
\hline Utstyr ventrikkeltømming & 94 & (45) & 77 & 10 & 7 \\
\hline Utstyr gipsing & 93 & (44) & 77 & 6 & 10 \\
\hline $\begin{array}{l}\text { Skop til hjerteover- } \\
\text { våkning }\end{array}$ & 89 & (42) & 59 & 5 & 25 \\
\hline Intraossøs kanyle & 69 & (33) & 54 & 6 & 9 \\
\hline Utstyr senesutur & 54 & (25) & 38 & 4 & 12 \\
\hline Ultralydapparat & 30 & (14) & 20 & 3 & 7 \\
\hline Røntgenapparat & 28 & (13) & 16 & 4 & 8 \\
\hline Alkometer & 11 & (5) & 5 & 0 & 6 \\
\hline
\end{tabular}

Apparatur og utstyr til diagnostikk og behandling

Tabell 1 viser hvor hyppig ulike typer utstyr er tilgjengelig for lege på vakt. Røntgen- og ultralydapparat og alkometer er lite utbredt, mens over $90 \%$ har tilgang på EKG, urinkateter, otoskop og oftalmoskop samt utstyr til sårsutur, gynekologisk undersøkelse og intravenøs tilgang. Nesten alle hadde også utstyr for øyeskylling, forstøverapparat, utstyr for oksygentilførsel og defibrillator. Akuttsekk og markeringsjakke til bruk ved utrykning er i mindre grad tilgjengelig ved frittstående legevakter. Samlokaliserte legevakter er generelt bredere utstyrt enn frittstående legevakter, særlig gjelder dette de mindre.

\section{Laboratorieanalyser}

Seks laboratorieundersøkelser finnes ved så godt som alle legevakter: CRP, blodsukker, urinstrimmel, svangerskapstest, streptokokkantigentest og hemoglobin ( $\operatorname{tab} 2$ ). Bare noen få legevakter har mulighet for kliniskkjemiske analyser som kalium, ALAT og kreatinin. Hurtigtester for CK-MB, D-dimer og troponin har også liten utbredelse. INRmåling er tilgjengelig ved hver fjerde legevakt. Det gjelder først og fremst de samlokaliserte, der man i stor grad disponerer analyseutstyret sammen med legekontoret, mens det bare er $3 \%$ (to av 59) av de frittstående legevaktene som analyserer INR. En tilsvarende tendens finner vi også for $\mathrm{HbA}_{1 \mathrm{c}}$ og celletelling. I motsetning til dette er det vanligere med testsett for mononukleose og Chlamydia ved frittstående legevakter.

\section{Medikamenter}

Ved alle legevakter oppbevares det medikamenter, og de fleste lagerfører et bredt spekter (e-tab 3). Tilgangen på legemidler styres i stor grad av at legevaktene selv kjøper inn og oppbevarer medikamenter, det er kun $5 \%$ av legevaktene som opplyser at vaktlegen har ansvar for innkjøp. Av de legevaktene som selv kjøper inn medikamenter, oppgir $44 \%$ at de selger enkeltdoser som skal holde til apoteket åpner. $48 \%$ har også minstepakninger for salg, mens noen få legevakter bare har medikamenter til eget bruk. Det var små forskjeller mellom samlokaliserte og frittstående legevakter.

Når det gjelder gruppen preparater til injeksjon (e-tab 3), har mer enn $90 \%$ adrenalin, hydrokortison, metoklopramid, tetanus-/difterivaksine, opiater, diklofenak, diazepam, nalokson og atropin. Generelt er små samlokaliserte legevakter best utstyrt, frittstående legevakter har færrest injeksjonspreparater, mens samlokaliserte større legevakter kommer i en mellomstilling. Antibiotika til injeksjon, antiarytmika og antitrombotiske midler til bruk ved hjerteinfarkt finnes i langt større grad ved samlokaliserte legevakter, og særlig ved de minste.

Ved mange legevakter er det et stort utvalg perorale medikamenter. Her står små legevakter $\mathrm{i}$ en særstilling - med et bredere 
utvalg enn de øvrige to gruppene. Dette gjelder anxiolytika som diazepam, antipsykotika, sovemidler og opiater, men også antibiotika som dikloksacillin og klindamycin, laksantia og warfarin, og i noen grad også migrenemidler og karbamazepin. Inhalasjonspreparater og noen lokale midler har de aller fleste (e-tab 3).

\section{Noen rutiner ved legevaktene}

Det oppgis at øvelse i avansert hjerte-lungeredning for $52 \%$ av legene arrangeres regelmessig og minst én gang årlig, 31\% øver sjeldnere enn dette og $17 \%$ aldri. Ved samlokaliserte legevakter øver hjelpepersonellet nesten like ofte som legene $-55 \%$ årlig eller oftere, mens legene har øvelse årlig eller oftere i $60 \%$ av tilfellene. Ved frittstående legevakter øver hjelpepersonellet oftere enn legene $74 \%$ minst årlig, mot bare $40 \%$ for legene.

Ved små samlokaliserte legevakter tar og analyserer vaktlegen blodprøvene selv $\mathrm{i}$ $88 \%$ av tilfellene, sammenliknet med $56 \%$ ved større samlokaliserte legevakter. Intern og ekstern kvalitetskontroll ivaretas av legekontorets personell i nesten alle tilfeller. Ved frittstående legevakter $(n=59)$ er det i $90 \%$ av tilfellene ansatt hjelpepersonell som tar og analyserer blodprøver. Intern kvalitetskontroll utføres ved $86 \%$ av legevaktene av sykepleier, men også ambulansearbeidere er involvert i dette (ved 10\% av de frittstående legevaktene). Intern kvalitetskontroll utføres regelmessig ved $71 \%$ av legevaktene, ved $16 \%$ sporadisk eller sjeldnere enn hver uke, ved $4 \%$ bare ved mistanke om feil, mens det ved $8 \%$ ikke er rutiner for slik kontroll. $73 \%$ av de frittstående legevaktene har ekstern kvalitetskontroll gjennom eget medlemskap i NOKLUS.

$85 \%$ av legevaktene oppgir at alle ansatte har tilgang til bruksanvisning for all apparatur, og at nyansatte får demonstrasjon og gjennomgang av utstyret. Laboratoriepermene fra NOKLUS oppgis å være tilgjengelig hos $68 \%$. Forsendelse av prøvemateriale skjer ved bud hos $24 \%$ og ved postforsendelse hos $58 \%$ av legevaktene, mens $10 \%$ leverer selv.

Ved $67 \%$ av legevaktene er det skriftlige rutiner for håndtering av blodsøl og stikkskader, ved $19 \%$ er det vaktlegen som bestemmer tiltak, $7 \%$ lar medisinskfaglig ansvarlig lege ta ansvaret, mens $7 \%$ mangler rutiner. Fast ansatt helsepersonell făr tilbud om vaksine mot hepatitt B ved $64 \%$ av legevaktene - dette er vanligst ved frittstående legevakter, der andelen er $78 \%$.

\section{Diskusjon}

I denne studien har vi kartlagt hvilket utstyr, hvilke medikamenter og hvilke laboratorietester vaktlegen ved norske legevakter kan forvente å finne tilgjengelig. Med en svarprosent på 86 har vi data fra et representativt utvalg av ulike legevakter. Vi har undersøkt tilgangen på utstyr, ikke ferdigheter eller om bruken er korrekt. Resultatene kan ikke brukes som mal for hvilket utstyr som skal eller

Tabell 2 Antall legevakter med tilgjengelige laboratorieanalyser fordelt etter størrelse på legevaktdistriktet og samlokalisering med legekontor

\begin{tabular}{|c|c|c|c|c|c|}
\hline & \multicolumn{2}{|c|}{$\begin{array}{l}\text { Totalmateriale } \\
\qquad(N=209)\end{array}$} & \multirow[t]{2}{*}{$\begin{array}{c}\text { Samlokaliserte } \\
<10000 \\
\text { innbyggere } \\
\text { (n=125) }\end{array}$} & \multirow[t]{2}{*}{$\begin{array}{c}\text { Samlokaliserte } \\
>10000 \\
\text { innbyggere } \\
(n=25)\end{array}$} & \multirow[t]{2}{*}{$\begin{array}{l}\text { Frittstående } \\
\quad(n=59)\end{array}$} \\
\hline & Antall & $(\%)$ & & & \\
\hline CRP & 207 & (99) & 123 & 25 & 59 \\
\hline Urinstrimmel & 200 & (96) & 119 & 24 & 57 \\
\hline Glukose & 200 & (96) & 118 & 23 & 59 \\
\hline Urin-HCG & 194 & (93) & 118 & 20 & 56 \\
\hline Streptest & 193 & (92) & 113 & 22 & 58 \\
\hline Hemoglobin & 190 & (91) & 113 & 21 & 56 \\
\hline Blod i feces & 157 & (75) & 99 & 17 & 41 \\
\hline Urindyrking & 121 & (58) & 83 & 18 & 20 \\
\hline Mononukleosetest & 116 & $(56)$ & 57 & 14 & 45 \\
\hline Urinmikroskopi & 102 & (48) & 68 & 11 & 23 \\
\hline SR & 69 & (33) & 57 & 6 & 6 \\
\hline Chlamydiatest & 55 & (26) & 29 & 6 & 20 \\
\hline INR & 52 & (25) & 45 & 5 & 2 \\
\hline $\mathrm{HbA}_{1 \mathrm{c}}$ & 32 & (15) & 27 & 4 & 1 \\
\hline Celleteller & 28 & (13) & 21 & 5 & 2 \\
\hline Leukocytter & 22 & $(11)$ & 16 & 4 & 2 \\
\hline Trombocytter & 19 & (9) & 13 & 4 & 2 \\
\hline D-dimer & 13 & (6) & 9 & 1 & 3 \\
\hline Troponin & 12 & (6) & 7 & 0 & 5 \\
\hline ALAT & 8 & (4) & 4 & 1 & 3 \\
\hline Kreatinin & 8 & (4) & 4 & 1 & 3 \\
\hline Influensatest & 8 & (4) & 5 & 1 & 2 \\
\hline GT & 7 & (3) & 4 & 0 & 3 \\
\hline Urat & 6 & (3) & 3 & 0 & 3 \\
\hline Kalium & 5 & (2) & 2 & 1 & 2 \\
\hline CK-MB & 4 & (2) & 2 & 0 & 2 \\
\hline Kolesterol & 3 & (2) & 2 & 0 & 1 \\
\hline Helicobacter pylori & 4 & (2) & 4 & 0 & 0 \\
\hline Natrium & 3 & (1) & 1 & 0 & 2 \\
\hline
\end{tabular}

bør være tilgjengelig ved kommunale legevakter. Det er også ukjent om manglende utstyr ved legekontor eller legevakt kan medføre feilaktig medisinsk diagnostikk eller behandling prehospitalt. Dette bør undersøkes videre i oppfølgingsstudier.

Undersøkelsen viser at norske legevakter i stor grad er samlokalisert med legekontorer og at repertoaret av utstyr og laboratorieanalyser styres av dette. Frittstående legevakter har noe smalere repertoar. Dette kan skyldes at mange av de største legevaktene er sentralt lokalisert, med kort avstand til ambulanse, sykehus og apotek (2). Svært kompetansekrevende og kostbart utstyr som ultralyd og røntgen er i liten grad tilgjengelig ved norske legevakter, og utstyr som rektoskop/anoskop, spirometer og utstyr til indirekte laryngoskopi finnes nok primært fordi det brukes på legekontoret. Utstyr som brukes til gipsing og ventrikkeltømming og intraossøs nål, derimot, er nok mest $\mathrm{i}$ bruk der det er en viss avstand til sykehus, det vil si helst ved mindre legevakter i perifere strøk. I enkelte legevaktdistrikter er det helseforetaket som tar all utrykning/rød respons (1), og dette kan forklare noe av den lavere tilgjengelighet på akuttmedisinsk utstyr og medikamenter vi finner ved frittstående legevakter. I tillegg ser vi at disse også i mindre grad oppbevarer Bog A-preparater. Dette kan ha flere forklaringer - mest nærliggende er det å anta at det forenkler hjelpepersonellets arbeid med forsvarlig oppbevaring, håndtering og utlevering av slike medikamenter. I den grad det finnes døgnåpne apoteker i rimelig nærhet, synes det heller ikke nødvendig.

Laboratorieanalyser brukes ved en tredel av legevaktkonsultasjonene, ifølge NAV-statistikk fra 2006. CRP-analyse er den mest brukte, idet $93 \%$ av regningskortene med takst for laboratorieanalyser også har påført takst for CRP (3). I undersøkelsen vår ser vi også at det store flertallet av legevaktene 
bruker tester som er enkle og raske å ta og analysere, mens det er svært få som bruker mer tidsmessig og kostnadsmessig krevende apparatur, som utstyr for klinisk-kjemiske analyser og celletelling, på legevakt.

Vi finner altså at både samlokalisering og hvor sentralt legevakten ligger er faktorer som kan forklare noen av de forskjellene vi har påvist, men i mangel av bestemmelser om hvilket utstyr som skal være disponibelt er det også nærliggende å anta at økonomiske forhold kan styre utvalget. Krav til nødvendig utstyr ved norske legevakter i form av nasjonale retningslinjer vil kunne minske disse forskjellene. Dette finnes ikke i dag, bortsett fra en generell veiledning i Legevakthåndboken. Det er ukjent i hvilken grad denne og andre kilder blir brukt i denne sammenheng, slik at det er begrenset i hvilken grad våre funn kan relateres til de anbefalinger som finnes. Det bør derfor utarbeides nasjonale retningslinjer for hvilket utstyr som skal være tilgjengelig og hvilken kompetanse personellet på legevakten bør ha.

Ved samlokaliserte legevakter er det i svært stor grad legekontorets personell som gjennomfører ekstern og intern kvalitetskontroll av laboratorieutstyret, samtidig som legevaktens personell og ulike vaktleger bruker utstyret. Spesielt vaktleger, men også sykepleiere, har generelt lite opplæring i og liten erfaring med laboratoriearbeid. Alle norske legekontorer er medlem av NOKLUS, men i denne undersøkelsen ser vi at av frittstående legevakter er det over en firedel som ikke er tilknyttet kvalitetskontrollsystemet til NOKLUS. En del har heller ikke tilgang til bruksanvisninger for laboratorieutstyret eller NOKLUS-permene.
Hvorvidt disse forholdene gir redusert kvalitet på prøvesvarene fra legevaktene, bør undersøkes nærmere.

Funnene rundt tilbud om hepatitt B-vaksinasjon sier lite om vaksinasjonsdekning, da de fleste som er utdannet de siste årene er vaksinert og vaktleger er selvstendig næringsdrivende på legevakt og ikke fast ansatt. Det viser imidlertid at det legges stor vekt på sikkerheten for de ansatte ved et flertall av legevaktene, selv om det fremdeles er mange som overlater til den enkelte ansatte å sørge for vaksinasjon.

Det er stor spredning i hyppighet av øvelse i avansert hjerte-lunge-redning. Øvelseshyppigheten er lavest for vaktleger ved større frittstående legevakter, mens den for hjelpepersonellet øker med økende legevaktstørrelse. Dette gjenspeiler sannsynligvis at større frittstående legevakter med ansatt hjelpepersonell og administrativt personell i et større fagmiljø har lettere for å gjennomføre systematiske øvelser. Med et høyt antall deltakende leger fra ulike kommuner ved interkommunale legevakter og mange sykehusleger som deltar ekstra på legevakt i byer/ tettsteder er det vanskelig å gjennomføre systematisk øvelse for alle (4-6). Det at mange leger øver sjeldnere enn årlig, kan over tid gjøre det vanskelig å opprettholde kompetansen i avansert hjerte-lunge-redning $(7,8)$. Også samhandlingen med ambulansepersonell og andre samarbeidspartnere kan lide under dette.

\section{Konklusjon}

Utstyrsnivå og analyserepertoar styres i stor grad av om legevaktlokalene er samlokalisert med legekontor, men trolig også av av- stand til ambulanse, sykehus og apotek. Det kan være uheldig at mye av laboratorieutstyret brukes av personell med liten laboratorieerfaring, og dette bør undersøkes nærmere. Trolig bør det satses mer på regelmessig trening $\mathrm{i}$ avansert hjerte-lunge-redning ved kommunale legevakter.

Oppgitte interessekonflikter: Ingen

e-tab 3 finnes i artikkelen på www.tidsskriftet.no

\section{Litteratur}

1. Zakariassen E, Blinkenberg J, Holm-Hansen E et al. Beliggenhet, lokaler og rutiner ved norske legevakter. Tidsskr Nor Lægeforen 2007; 127 $1339-42$.

2. Nieber E, Holm-Hansen E, Bondevik G et al. Organisering av legevakt. Tidsskr Nor Lægeforen 2007; 127: $1335-8$

3. NAV. Konsultasjonsstatistikk 2006. www.nav.no/ page? $i d=1073743201 \&$ queryparameter=konsultasjonsstatistikk (8.12.2008).

4. Sandvik H, Zakariassen E, Hunskår S. Fastlegenes deltakelse i legevakt. Tidsskr Nor Lægeforen 2007; 127: $2513-6$

5. Otterlei B, Bentzen N. Færre fastleger deltar i legevakt. Tidsskr Nor Lægeforen 2007; 127: 1351-3.

6. Utsi R, Brandstorp $\mathrm{H}$, Johansen $\mathrm{K}$ et al. Tverrfaglig akuttmedisinsk teamtrening i kommunehelsetjenesten. Tidsskr Nor Legeforen 2008; 128: 1057-9.

7. Norsk resuscitasjonsråd. Reviderte krav til AHLRutøvere mai 2008. www.nrr.org/index1.html (17.9.2008)

8. Zakariassen E, Sandvik H, Hunskår S. Norwegian regular general practitioners' experiences with out-of-hours emergency situations and proced ures. Emerg Med J 2008; 25: 528-33.

Manuskriptet ble mottatt 22.9. 2009 og godkjent 8.1. 2009. Medisinsk redaktør Åslaug Helland. 